\title{
Relevance of Visual, Auditory, and Olfactory Cues in Pet Dogs' Awareness of Humans
}

\author{
Megumi Fukuzawa*, Marina Watanabe \\ Nihon University, College of Bioresource Sciences, Department of Animal Science and Resources, Laboratory of Companion \\ Animal, 1866 Kameino, Fujisawa, Japan \\ Email: ^fukuzawa.megumi@nihon-u.ac.jp
}

How to cite this paper: Fukuzawa, M. and Watanabe, M. (2017) Relevance of Visual, Auditory, and Olfactory Cues in Pet Dogs' Awareness of Humans. Open Journal of Animal Sciences, 7, 297-304. https://doi.org/10.4236/ojas.2017.73023

Received: April 8, 2017

Accepted: July 9, 2017

Published: July 12, 2017

Copyright (c) 2017 by authors and Scientific Research Publishing Inc. This work is licensed under the Creative Commons Attribution International License (CC BY 4.0).

http://creativecommons.org/licenses/by/4.0/

\section{c) (i) Open Access}

\begin{abstract}
Many studies have looked at how dogs respond to human communicative information. Here, we examined which human communicative factors were important in influencing dogs' responses. Eleven healthy pet dogs with no apparent aggressive behaviour toward people were recruited. Five sensory conditions (all cues presented; either a visual, an auditory, or an olfactory cue presented; no cues presented) were provided three times randomly to each dog during the tests. All tests were video recorded, and both the dogs' behaviour and time taken to reach the person when she presented each of the sensory cue conditions were observed. Total rates of reaching the person were as follows: $97.0 \%$ (all cues), $87.9 \%$ (auditory cues), $84.4 \%$ (visual cues), $84.4 \%$ (olfactory cues), and $69.7 \%$ (no cues). The time taken for the dog to notice the person in the box and then obtain a reward from her differed among the five conditions: all cues $(6.00 \pm 0.32 \mathrm{~s})$ and visual cues $(6.02 \pm 0.91 \mathrm{~s})$ were significantly faster than auditory cues $(18.56 \pm 9.57 \mathrm{~s})$ and no cues $(26.55 \pm 11.72 \mathrm{~s})$. Thus the type of information input was important in recognition of the person by the dogs and influenced the dogs' response times; visual cues appeared advantageous in confirming the person's presence.
\end{abstract}

\section{Keywords}

Behavioural Response, Dog, Human Communicative Cues

\section{Introduction}

Over the centuries, dogs have built up close relationships with humans, and recently there have been studies of how dogs use visual or olfactory perception to recognise a person facing them. It has been suggested that since their domestication dogs have had strong sensitivity to human communicational signals [1] [2]. Although there are breed differences in the early stages of development of do- 
mesticated dogs (ex. vocalisation), development of the organs and other physical characteristics associated with a dog's neurological senses commonly starts at about 3 weeks of age. After dogs start learning to recognize their surrounding environment and to communicate with other dogs and humans, they also start to approach new stimuli positively [3].

Mongillo et al. [4] observed the gazing behaviour of pet dogs when an owner or an unknown person appeared in front of them. The time spent gazing at an owner was longer than that spent gazing at the unknown person, but the time declined when the owner's or the unknown person's face was covered. Gazing behaviour is influenced also by whether a dog can distinguish a face and whether a person is present in front of the dog. It also seems to be influenced by the dog's age (and accordingly by its level of attachment to their owner). On the other hand, studies of trainers' body language and the distance between trainer and dog have investigated the effects of non-verbal signals and trainer position on the response of dogs during training to two verbal commands "sit" and "come" [5]. The difference in distance between the trainer and the dog after the dog had responded to each of these commands seemed to influence dogs' learning state. For awareness of human vocabulary, there is a report that a dog can recognise changes in consonants in the verbal command sounds of a trainer and can respond to them correctly [6]. For human odour, a dog can distinguish differences in the odours of secretions extracted from different parts of the same person, as well as differences in odours among people [7]. There have therefore been a lot of reports about the ability of dogs to perceive human auditory and olfactory information. However, to our knowledge there have been no reports on the relative dominance of the different senses in dogs responding to human communicative cues. Our aim here was to determine which human communicative factors influenced the dogs' responses.

\section{Materials and Methods}

\subsection{Animals}

Eleven healthy pet dogs ( 2 female German shepherds, 2 male golden retrievers, 1 female Labrador retriever, 1 female border collie, 1 female toy poodle, and 4 crossbreds ( 1 female and 3 males) participated in the study. All dogs were kept in their owners' houses during the juvenile period and had not shown aggressive behaviour toward humans (including unknown humans) in the period before study participation. The dogs varied in age (from 6 to 89 months) and in weight (from 3.5 to $33.7 \mathrm{~kg}$ ). All dogs were allowed contact with the outside environment and with humans at any time while staying at the university to participate in the tests.

\subsection{Experimental Area}

A room at Nihon University was used for the experiment, and the experimental box was placed in this room (Figure 1). The box contains an observation area, a dog starting area, and a human staying area. A female observer who was sitting silently was located on the back of dog starting area after a dog entered the 


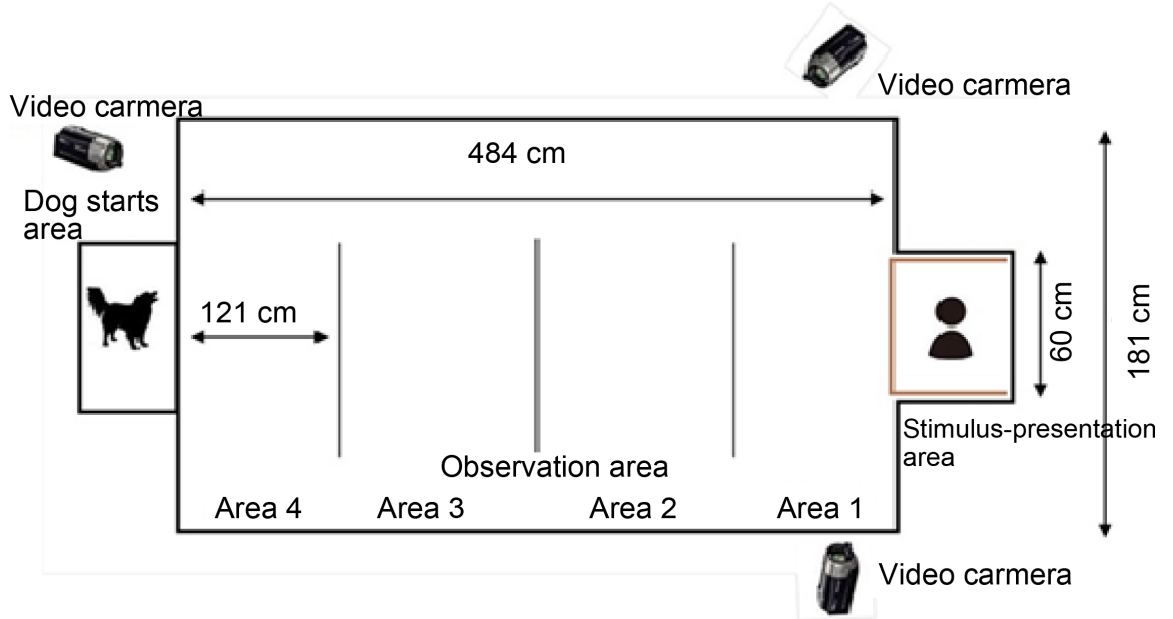

Figure 1. Plan of experimental area.

observation area. Three video cameras were used to record the dogs' behaviour during each test. The room temperature was controlled at around $23.0^{\circ} \mathrm{C}$ (mean temperature, $22.3^{\circ} \mathrm{C} \pm 0.28^{\circ} \mathrm{C}$ ).

\subsection{Experimental Conditions}

Five experimental conditions were set up as described below. The person who was present in the room (a female in her $20 \mathrm{~s}$ ) was the same throughout the tests and was familiar with all of the dogs. Each condition was presented randomly three times for each dog.

All cues conditions: All cues were presented, so the dog could confirm that the person was present by using by visual, auditory, and olfactory information. The man who sat in the box avoided making eye contact with the dog and read a newspaper out loud continuously, without emotion, during the test. The voice volume was set at about $50 \mathrm{~dB}$. Therefore, the dog could recognise the person's existence by using visual (the person's figure), auditory (the person's voice), and olfactory (the person's odour) information.

Visual conditions: Only visual cues were presented, so the dog could confirm the person's presence only by using visual information. The person wore a raincoat and sat with closed mouth in the boxed area. An aroma diffuser (Dretec Inc. Saitama, Japan) with lavender essential oil ( $50 \mu \mathrm{l}$ oil $+70 \mathrm{ml}$ water) was operated to eliminate the person's odour. The person avoided making eye contact with the dog, dropping naturally her gaze toward the dog's feet.

Auditory conditions: Only auditory cues were presented, so the dog could confirm the person's presence only by using auditory information. The person read a newspaper out loud continuously without emotion during the test. The voice volume was set at about $50 \mathrm{~dB}$. To restrict visual information, a screen was placed between the dog's area and the person's area. The person wore a raincoat, and the aroma diffuser with lavender oil ( $50 \mu \mathrm{loil}+70 \mathrm{ml}$ water) was operated.

Olfactory conditions: Only olfactory cues were presented, so the dog could confirm the person's presence only by using olfactory information. A circulator 
fan (Honeywell, Massachusetts, USA) was placed on the person's back during the test. The aroma diffuser was not operated but was located in the same position as in the other conditions.

No cues conditions: No cues were presented, so the person's area was empty. The screen was in place; both the aroma diffuser and the circulator were located in the same positions but were not operated during the test.

\subsection{Experimental Procedure}

While the observer (the woman in her $20 \mathrm{~s}$ ) took the dog outside for toileting, a man entered the boxed area and sat motionless on standby. The dog, which was equipped with a heart rate monitor (POLAR Electro Oy, Kampele, Finland),was then brought to stand in the dog start area. After the observer had confirmed that the dog's heart rate was within the normal range, the observer opened the door leading to the observation area and began observations. When the dog had moved into the observation area and noticed the presence of the man and approached her, a reward (a piece of beef jerky) was supplied automatically and randomly from the front panel. The dog's behaviour was recorded for $75 \mathrm{~s}$ after reward acquisition. If the dog did not get a reward (i.e. if it did not approach the box), observation was stopped after $120 \mathrm{~s}$. After each observation time had ended, the observer returned the dog to the start area and removed the heart rate monitor.

\subsection{Behavioural Categories}

Three video cameras (Sony Inc. Tokyo, Japan) were used to record the dog's behaviours (Table 1) during each test. Both the area in which the dog was located (areas 1 to 4 ; see Figure 1) and the behaviour of the dog were checked on the recorded images. The area in which the dog was located was considered to be the

Table 1. Ethogram used in the study.

\begin{tabular}{ll}
\hline Observational category & Description \\
\hline Approaching & Dog opens mouth widely and exhales \\
Tail wagging & Dog licks its mouth or nose \\
Panting & Dog pants with open mouth \\
Scratching & Dog scratches its body \\
Stretching & Dog stretches its forelegs or hind legs \\
Yawning & Dog opens mouth widely and exhales \\
Sniffing & Dog sniffs the air or the experimental materials \\
Grooming & Dog grooms its body with its tongue \\
Shaking & Dog shakes its body \\
Refusing & Dog tries to get away from the experimental area \\
Jumping & Dog jumps up into the air \\
Freezing & Dog maintains the same posture over $3 \mathrm{~s}$ \\
Others & Barking, whining, excretion, etc. \\
\hline
\end{tabular}


one in which more than half of its body was located. If the dog's body spanned two areas equally, the area chosen was that in which the forward part of the body was located. The number of seconds spent in each behaviour was recorded by using a continuous observational method.

\subsection{Statistical Analysis}

The initial analysis used a repeated-measures analysis of variance to assess the effect of the experimental conditions and the subject, as well as repetitions of the response time (time taken for the dog to reach the man in the box, stop, and obtain a reward), the time spent in each area (1 to 4 ) during the test, or the time spent in each behaviour. Post hoc Tukey tests were used for pairwise comparison of the means of the response times or the times spent in each area or in each behaviour when significant effects were found.

\section{Results}

\subsection{Total Rates of Reaching the Person, and Response Times}

The total reaching rates under each sensory condition were 97.0\% (all cues), $87.9 \%$ (auditory cues), $84.4 \%$ (visual cues), $84.4 \%$ (olfactory cues), and $69.7 \%$ (no cues). The response times until the dogs obtained the reward differed significantly among experimental conditions: response times with all cues $(6.00 \pm$ $0.32 \mathrm{~s})$ and visual cues $(6.02 \pm 0.91 \mathrm{~s})$ were significantly faster than those with auditory cues (18.56 $\pm 9.57 \mathrm{~s}$ )and no cues $(26.55 \pm 11.72 \mathrm{~s})$ (Tukey, $p<0.05)$. The response time with olfactory cues $(14.82 \pm 3.62 \mathrm{~s})$ did not differ significantly from those under the other conditions.

\subsection{Time Spent in the Area}

The time spent in each area before reward acquisition differed among conditions: the times spent in area 1 (closest to the man)under all cues, visual cues, and auditory cues were longer than those spent in the other three areas (Tukey, $p<0.05$ for each). However, there were no differences in times among areas in the case of olfactory cues and no cues (Figure 2). Furthermore, the amounts of time spent in each area by dogs that were unsuccessful in getting a reward did not differ under any of the conditions.

The times spent in each area after reward acquisition differed among conditions: the times spent in area 1 were longer than those spent in other areas under all cues, visual cues, auditory cues, and olfactory cues (Tukey, $p<0.05$ ). In contrast, the time spent in area 4 (next to the dog start area) was longer than those spent in the other areas in the case of no cues (Tukey, $p<0.05$ ) (Figure 3 ).

\subsection{Behaviours}

We examined the influence of each condition on each behaviour category. There was a significance difference in "sniffing" behaviour before reward acquisition: "sniffing" times under all cues ( $0.78 \pm 0.36 \mathrm{~s})$, visual cues $(1.89 \pm 0.91 \mathrm{~s})$, and olfactory cues $(4.37 \pm 1.35 \mathrm{~s})$ were shorter than those under no cues $(8.65 \pm 2.50 \mathrm{~s})$ 


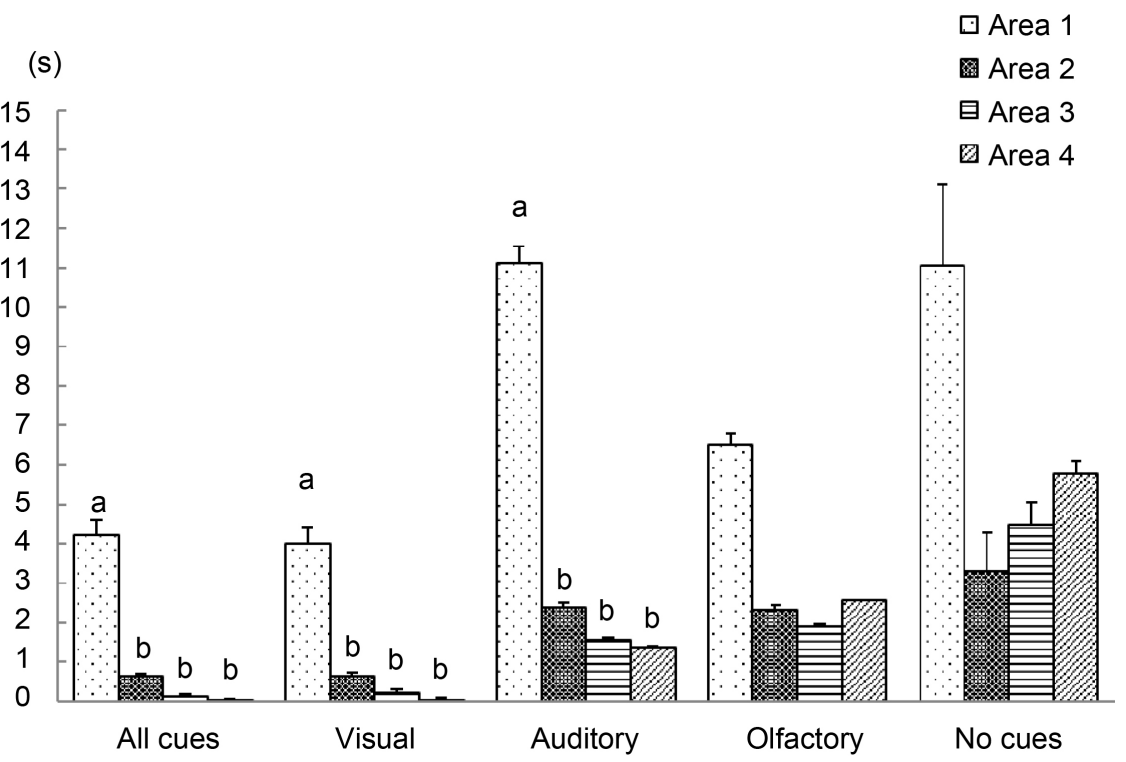

Figure 2. Means and standard deviations of times spent in each area under each condition before reward acquisition ( $\mathrm{a}$ and $\mathrm{b}$, Tukey, $p<0.05$ under each condition).

(Tukey, $p<0.05)$. However, sniffing times with auditory cues (5.66 $\pm 1.81 \mathrm{~s})$ did not differ from those under the other conditions.

There were significance differences among conditions in both "tail wagging" and "freezing" behaviour after reward acquisition: "tail wagging" time with visual cues $(23.22 \pm 3.96 \mathrm{~s})$ was longer than that with auditory cues $(8.93 \pm 2.47 \mathrm{~s})$ or olfactory cues (7.85 $\pm 2.30 \mathrm{~s}$ ) (Tukey, $p<0.05)$. Time spent "freezing" was longer with no cues $(21.87 \pm 4.41 \mathrm{~s})$ than with all cues (8.56 $\pm 2.41 \mathrm{~s}$ ) (Tukey, $p<$ $0.05)$.

\section{Discussion}

It was clear that the type of communicative factor influenced the dogs' perception when it recognized the person's existence.

The results for total reaching rate and response time indicated that if the dog was able to acquire only visual or auditory or olfactory information it was still able to apply this information effectively. There have been many reports of dogs' sensitivity to human visual information [1] [2] [8]. For example, dogs can perceive from the human gaze what is required and respond appropriately to that information, and the mere presence of a human can influence a dog's response. Moreover, it is clear that, during dog training, a dog's performance is influenced by both the distance between trainer and dog and non-verbal signals (i.e. hand signals and body language) [9]. Visual-only information was related more than auditory-only information to the earliness of a dog's reaction in our experiment. Therefore, the presence of visual information may be more important to the dog's reaction.

The time spent in each area was also influenced by human information. Before reward acquisition, dogs able to receive information cues from the man just 


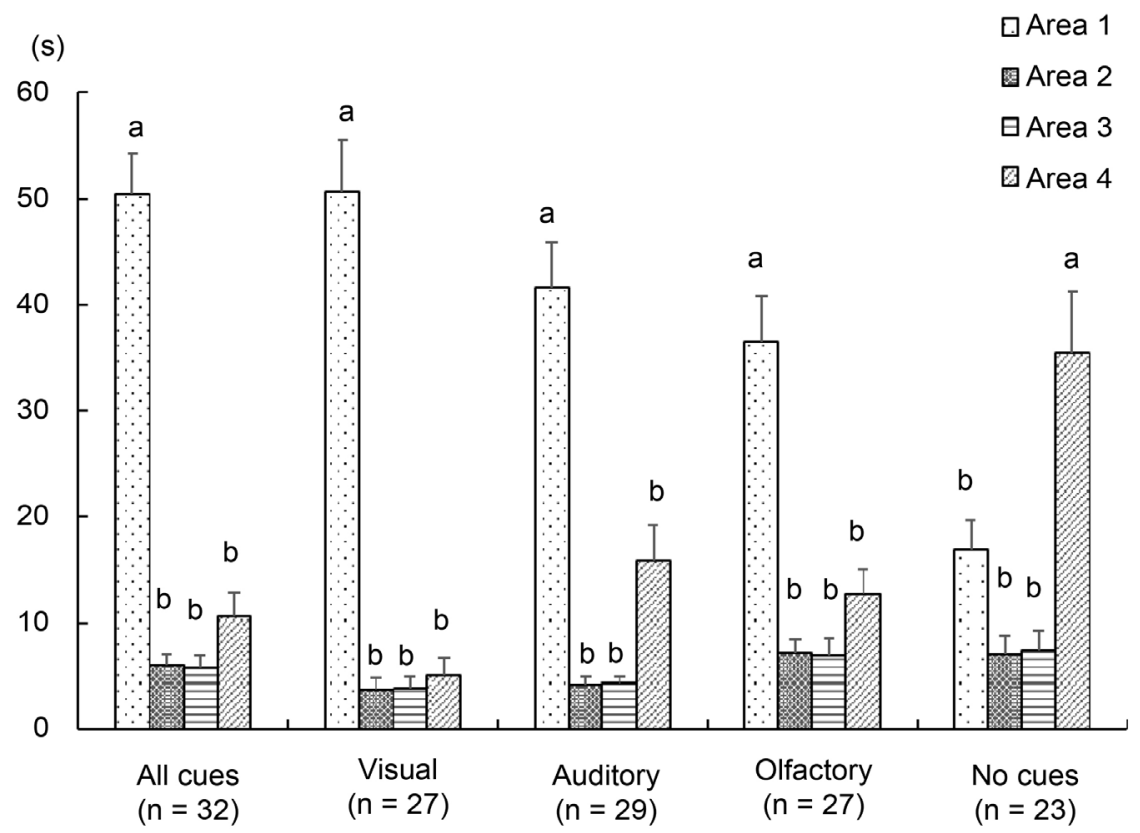

Figure 3. Means and standard deviations of times spent in each area under each condition after reward acquisition ( $\mathrm{a}$ and $\mathrm{b}$, Tukey, $p<0.05$ under each condition).

after they had entered the room moved close to the man's area immediately. There was a trend for visual and olfactory information to give a more rapid response than auditory information, but no significant difference was found. The times spent "sniffing" also differed among conditions, but there was no difference among [olfactory], [visual], and [auditory] conditions. The time spent "sniffing" with no cues was significantly longer than under the other three (excluding auditory) conditions. One study has found that the duration of "sniffing" in detector dogs is shortest when the target odour is not present; the dogs indicate this by not offering an alert response (true negative) [10]. However, we observed that "sniffing" was longer when no odour was present than when it was. The behavioural definition may differ between "sniffing" close to the scent target by a trained detector dog and "sniffing" freely in the area used in our study.

After reward acquisition, a long time was spent in the area next to the person's box in the case of olfactory, auditory, visual, and all cues. On the other hand, the time spent on returning to the area next to the start, and staying there, was significantly longer than the times spent in the other areas when there were no cues (i.e. when the man was absent). Dogs that recognised the presence of the man likely wanted to spend more time near her. The time spent "tail wagging" was significantly longer with visual cues than with auditory or olfactory cues. In contrast, there were no differences in the other behaviours, including negative emotions, among cue conditions. Therefore, visual information may have a positive influence on dogs' responses. The time spent "freezing" was longer with no cues, but this may have been because the dogs tried to restrain their own movement and minimise stimulation from the surrounding environment. One 
review has found that human factors, including personality and attitudes, influence the dog-human relationship [11]. The relationship between the dog and the person in our experiment may also have influenced the time spent in each area. If the person in the box had been a woman with which the dogs were familiar, they may have spent even more time in area 4 reward acquisition.

\section{Conclusion}

Visual, auditory, and olfactory information are all important for dogs in confirming the presence of a human, but visual information appears to have an advantage for dogs' perception.

\section{References}

[1] Soproni, K., Miklósi, A., Topál, J. and Csányi, V. (2001) Comprehension of Human Communicative Signs in Pet Dogs (Canisfamiliaris). Journal of Comparative Psychology, 115, 122-126. https://doi.org/10.1037/0735-7036.115.2.122

[2] Soproni, K., Miklósi, A., Topál, J. and Csányi, V. (2002) Dogs' Responsiveness to Human Pointing Gestures. Journal of Comparative Psychology, 116, 27-34. https://doi.org/10.1037/0735-7036.116.1.27

[3] Houpt, A.K. (2005) Domestic Animal Behavior for Veterinarians and Animal Scientists. 4th Edition, Blackwell Publishing, Iowa, USA.

[4] Mongillo, P., Bono, G., Regolin, L. and Marinelli, L. (2010) Selective Attention to Humans in Companion Dogs, Canisfamiliaris. Animal Behavior, 80, 1057-1063. https://doi.org/10.1016/j.anbehav.2010.09.014

[5] Fukuzawa, M., Uetake, K. and Tanaka, T. (2010) Effect of Changing Human Visible Information on Obedience in Dogs (Canisfamiliaris). Animal Behaviour and Management, 46, 61-68.

[6] Fukuzawa, M., Mills, D.S. and Cooper, J.J. (2005b) The Effect of Human Command Phonetic Characteristics on Auditory Cognition in Dogs (Canisfamiliaris). Journal of Comparative Psychology, 119, 117-120.

https://doi.org/10.1037/0735-7036.119.1.117

[7] Brisbin, I.L. and Austad, N.S. (1991) Testing the Individual Odour Theory of Canine Olfaction. Animal Behavior, 42, 63-69. https://doi.org/10.1016/S0003-3472(05)80606-2

[8] Gácsi, M., Miklósi, A., Varga, O., Topál, J. and Csányi, V. (2004) Are Readers of Our Face Readers of Our Minds? Dogs (Canisfamiliaris) Show Situation-Dependent Recognition of Human's Attention. Animal Cognition, 7, 144-153. https://doi.org/10.1007/s10071-003-0205-8

[9] Fukuzawa, M., Mills, D.S. and Cooper, J.J. (2005a) More Than Just a Word: Non-Semantic Command Variables Affect Obedience in the Domestic Dog (Canisfamiliaris). Applied Animal Behaviour Sciences, 91, 129-141. https://doi.org/10.1016/j.applanim.2004.08.025

[10] Concha, A., Mills, D.S., Feugier, A., Zulch, H., Guest, C., Harris, R. and Pike, W.T. (2014) Using Sniffing Behavior to Differentiate True Negative from False Negative Responses in Trained Scent-Detection Dogs. Chemical Senses, 39, 749-754. https://doi.org/10.1093/chemse/bju045

[11] Payne, E., Bennett, C.P. and McGreevy, D.P. (2015) Current Perspectives on Attachment and Bonding in the Dog-Human Dyad. Psychology Research and Behavior Management, 8, 71-79. https://doi.org/10.2147/PRBM.S74972 
Submit or recommend next manuscript to SCIRP and we will provide best service for you:

Accepting pre-submission inquiries through Email, Facebook, LinkedIn, Twitter, etc. A wide selection of journals (inclusive of 9 subjects, more than 200 journals)

Providing 24-hour high-quality service

User-friendly online submission system

Fair and swift peer-review system

Efficient typesetting and proofreading procedure

Display of the result of downloads and visits, as well as the number of cited articles Maximum dissemination of your research work

Submit your manuscript at: http://papersubmission.scirp.org/

Or contact ojas@scirp.org 